gest that different cells produce antibodies of different affinities but that the immunoglobulins produced by one cell are homogeneous. No immunoglobulin class disappears completely after whole body irradiation of mice; amino-acid incorporation has shown that one day after 950 rads all classes are produced. A primary immune response has been induced in an entirely in vitro system, which seems to favour the view that lymphoid cells are multipotent and can form antibody without division when forced to do so.

In thymectomized X-irradiated mice, grafted with a thymus and with restored bone-marrow, two populations of cells have undergone mitosis after antigenic stimulation; these were cells derived from thymus and bone-marrow respectively. In animals thymectomized, but not grafted with a thymus, no detectable antibody has been found nor has antigenic stimulation caused an initial mitotic increase, which is further evidence that cells of thymic origin must divide before a population of cells from bone-marrow can proliferate and go on to form antibody. It has been confirmed that cells from bone-marrow can effectively re-equip the irradiated recipient's immune system only as long as the thymus is present.

Foetal liver is believed to be relatively poor in immuno-competent cells and has been used to restore lethally irradiated rhesus monkeys. Although up to $10^{9}$ cells $/ \mathrm{kg}$ have been injected as therapy, restoration of haematopoietic function has been achieved very rarely. Furthermore, the animals receiving allogeneic foetal cells developed the "secondary radiation syndrome" probably caused by a graft versus host reaction. When bone-marrow was transplanted into supralethally irradiated dogs, the rapid appearance of hyperbasophilic cells in the peripheral blood within a few days of bone-marrow therapy was indicative of a strong graft versus host response. This type of cytological transformation seems to be restricted to the dog. To render bone-marrow cells less likely to cause graft versus host attack, pre-incubation of immuno-competent cells at $37^{\circ} \mathrm{C}$ has been employed. This reduced the graft versus host response and indicated that the immunological potential of incubated lymph node cells had been reduced.

A substantial proportion of irradiated rats receiving allogeneic bone-marrow cells have developed myelofibrosis, occurring simultaneously with marked haemopoietic activity in the marrow. Part of the aetiology of this syndrome might be a delayed graft versus host rejection phenomenon. Heavily irradiated $(10,000$ 30,000 r.) tissue undergoes a change, as indicated by the second-set like rejection of irradiated isografts.

\section{Dangerous Life}

THE hazards of modern life were discussed last week by the British Academy of Forensic Sciences at its annual scientific meeting held at the Institute of Psychiatry at the Maudsley Hospital. Mr. R. Kell explained how prolonged exposure to noise, which he defined as "sound unwanted by the recipient", can cause deafness. A survey of female jute weavers in Dundee has shown that after twenty years working with the looms, which may produce $100 \mathrm{~dB}$ and more -a very loud noise-there is considerable loss of hearing for sounds which have a frequency of around
4,000 cycles/sec. This loss of hearing is not usually noticed until it extends into the frequency range of speech, when the inability to hear sounds of particular frequencies can make speech almost or wholly unintelligible. This is at the moment very difficult to mitigate, because hearing aids which are merely amplifiers of sound cannot help when the ear is unable to respond to certain frequencies. The deafness develops because noise of an intensity greater than about $110 \mathrm{~dB}$ can eventually destroy the nerve cells on the basilar membrane in the inner ear, which produce electrical potentials when stimulated by sound of a particular frequency. The ear drum rarely busts and when it does usually heals up again. Once the nerve cells have been destroyed their particular frequency of sound cannot be heard again.

Loss of hearing is not only an occupational hazard; noisy hobbies such as rifle shooting can have the same effect, and some deafness has been found in pop singers and musicians who play loud instruments such as the bagpipes. Traffic is now the most common source of noise outside factories and the engine rooms of ships.

Discussing the hazards of breathing in the modern world, Dr A. E. J. Eggleton of the AERE, Harwell, described how air pollution by carbon monoxide is increasing as more cars produce more exhaust fumes. The concentration of this gas in Fleet Street on a normal summer day has been found to show two peaks, one at $9.00 \mathrm{a} . \mathrm{m}$. and the other at 6.00 p.m., when the density of traffic is greatest. This is the pollutant the concentration of which on the air comes nearest to the maximum permitted industrial concentration of 100 p.p.m., and 200-300 p.p.m. have been recorded in busy streets. Other dangerous pollutants include smoke, sulphur dioxide, oxides of nitrogen and carcinogenic hydrocarbons, although in most cases it is very difficult to correlate their concentrations in the air with mortality and morbidity.

\section{Molecules Constrained}

\section{from our Correspondent in Thermodynamics}

AN exceedingly elegant demonstration of how to calculate the thermodynamic properties of an assembly of polymer molecules each of which is subjected to some topological constraint has been provided by Professor S. F. Edwards of the University of Manchester in the current issue of the Proceedings of the Physical Society $(91,513 ; 1967)$. Elegance apart, the calculation will be of great interest to those concerned to account for the properties of materials such as rubber or glass, usually in terms of chemical linkages between different molecules. Edwards's analysis suggests that the properties of polymer molecules lumped together in bulk may be at least in peurt explicable by the fact that molecules in such assemblages are inevitably subjected to topological constraints of various kinds. It remains to be seen whether the simple calculations which he has now provided will prove capable of generalization to more realistic models, but there is at least some room for improvement.

In the simplest model of a constrained assemblage, identical molecules are supposed free to move in two dimensions and each of them is fixed at the ends to two fixed points. A constraint is provided by supposing that the end of an impenetrable rod is placed on 